Winter 2018

\title{
Against Expertise: The Current Case for Breadth over Depth
}

Jennifer Malkowski

Smith College, jmalkows@smith.edu

Follow this and additional works at: https://scholarworks.smith.edu/fls_facpubs

Part of the Film and Media Studies Commons

\section{Recommended Citation}

Malkowski, Jennifer, "Against Expertise: The Current Case for Breadth over Depth" (2018). Film Studies: Faculty Publications, Smith College, Northampton, MA.

https://scholarworks.smith.edu/fls_facpubs/1 


\title{
Against Expertise: The Current Case for Breadth over Depth
}

\author{
by JENNIFER MALKOWSKI
}

C inema studies scholars have long existed in a mode of defending our expertise and policing the borders of our discipline on the lookout for presumptuous nonexperts. In teaching, for example, film is a go-to pedagogical tool used across disciplines that consistently draws student interest. But as many of us have asserted in our institutions, it is also a medium with a complex history, situated in specific industrial and cultural contexts, deeply influenced by the evolutions of technology, and characterized by a rich array of aesthetic conventions. In other words, film isn't simple. It shouldn't be casually appropriated by untrained faculty in attempts to engage students or boost enrollments in atrophying majors.

For all our resentment of these practices, though, we must remember that cinema studies was founded by "nonexperts" - as all disciplines must be. The very type of film-centered English classes that some of us dismiss, for example, taught by instructors without formal cinema studies training were once gestation points for the mature discipline we are today. Examining the history of cinema studies, most of our departments, programs, and majors were created and nurtured in "traditional" departments at our institutions - often in the years before their faculty had or could possibly have had a $\mathrm{PhD}$ in cinema studies. And even today, we should acknowledge that there may be a lens that language and literature disciplines can apply to the study of film that we "pure" cinema studies scholars cannot - a reason to teach films in these classes, too, that we miss when we enshrine ourselves as the exclusive authorities on this medium.

In considering the questions posed by Lucas Hilderbrand for this In Focus, I begin here with the legacy of the outsider nonexpert because I would like to advocate for the value of the insider nonexpert within cinema and media studies, a field that is widening at a breakneck pace. In this piece, I seek to challenge the enshrined, seemingly innate value of expertise itself, putting it into the context of our current disciplinary moment and exposing what is lost when we doggedly and automatically pursue expertise. As an alternative to its deep-drilling mode, I argue for the timely importance of breadth over depth in an age of rapid technological expansion and the unprecedented convergence of media. My call is timely, I maintain, even when the value of expertise is being crudely and dangerously dismissed on the political stage; I am 
firmly opposed to those dismissals and hope to present here a specific and nuanced perspective on cinema and media studies expertise, and one that upholds the value of higher education. The commitment to breadth that I am promoting is particularly essential in our pedagogy, as exemplified by existing models in small liberal arts colleges and in comparative media studies. ${ }^{1}$

In the years since SCS added "and Media" to become SCMS in 2002, our discipline has undergone a tremendously fast expansion with few precedents in other fields. Consider how many media forms - not just media texts - have come into popular use during that period, including mobile apps, social media, streaming video, animated GIFs, and contemporary virtual reality platforms. ${ }^{2}$ For a demonstration of our remarkable scope, look no further than the first time slot of the 2017 SCMS conference as a representative sample. In those twenty panels and workshops, presenters spoke about Orson Welles's use of music, VHS fandom, Google Earth software, festival programming for Arab cinema, 1960s television advertising, Twitch livestreaming of video-game play, climate visualizations, Elvis fan magazines, midcentury Chinese opera films, environmental cinema, Scalar-based analysis of 1950s Cinemascope, sociological filmmaking in the silent era, colonialist impulses in the Pokémon Go mobile game, and media production in Chicago. ${ }^{3}$ The implications of our field's increasing range are apparent in the very different kinds of knowledge and skills a scholar would need in order to work on any of these topics. How much expertise would the presenter on Scalar-based analysis of Cinemascope have in common with the presenter on festival programming for Arab cinema? Or the presenter on sociological filmmaking in the silent era with the presenter on Twitch video-game livestreaming? ${ }^{4}$

There has always been breadth in cinema studies, but I suggest that the gap between these aforementioned topics is much greater than the gap between scholars in the 1970s writing psychoanalytic film theory and those writing auteur criticism. That gap today is also greater - to return to my opening example - than the perceived gap between a scholar of the modern American novel's expertise within the field of English and her ability to teach a class on Hitchcock. Video games are as distant from film as film is from literature in this example, and yet cinema studies faculty can and should extend themselves to teach the highly influential medium of video games as part of their curriculum. I have heard colleagues at research universities dismiss as dilettantes people like that hypothetical English professor who teaches Hitchcock. But I argue that we need more alleged dilettantes within cinema and media studies - more faculty willing to explore constituent areas of our field beyond their own research agendas and to bring them together in their classes.

1 I am framing these concerns as pointedly intradisciplinary — urging us all to hold ourselves accountable to the everwidening scope of our discipline — rather than as interdisciplinary.

2 Some of these predate 2002, but all have come into prominence and common use since.

3 Each of these can be found in the official conference program, available at http://c.ymcdn.com/sites/www.cmstudies .org/resource/resmgr/2017_conference/SCMS2017Program_norooms.pdf. My apologies if I have misinterpreted the subject of any of these talks on the basis of their titles.

4 These presenters, respectively, are Sam Roggen, Michelle Baroody, Constance Balides, and Alexander Champlin. 
Another name for these supposed dilettantes is "small liberal arts college (SLAC) faculty" like me. Cinema and media studies programs at SLACs - where they exist in any freestanding form - generally have one or two (three, if they're lucky) permanent faculty appointments and a network of affiliates teaching occasional courses that intersect with their subject areas. Even when these programs were just cinema (and not media) studies, imagine the scholarly breadth and dexterity required of a single professor with the mandate to shoulder a school's entire core cinema studies curriculum. ${ }^{5}$ Far from staying close to her own expertise in teaching, that professor may personally have been offering courses on silent cinema, the studio era, global cinema, genres, theory, auteurs, cinema programming, and digital cinema. With the necessary (and usually overdue) move to incorporate media studies, the range of forms, eras, industries, technologies, and so on that such SLAC faculties are covering has become even more staggering.

Far from writing a desperate plea for help from your SLAC colleagues, I want to highlight the excitement and intellectual invigoration of working with a mandate like this for breadth in teaching. I've been aspiring to become this type of hardworking dilettante for most of my career, ever since my own undergraduate education at Oberlin College. During my graduate studies at UC Berkeley, I entered academia's more typical culture of tightly focused research agendas and single-topic courses, but I also saw that some of the best scholars in my field were embracing the breadth model - roaming broadly in their intellectual curiosity and not only digging deeply. Linda Williams was a role model for me in this respect (as in most things), as she had managed to contribute oft-taught and -cited scholarship to wide-ranging subfields on gender, race, horror, melodrama, pornography, and documentary. During my years at Berkeley, I watched Linda begin and complete a book-length project in television studies, a wholly unfamiliar field that she immersed herself in late in her career. Her distinguished record demonstrates that the breadth model I'm advocating is not just a liberal arts mind-set, and it is possible in research as well as in teaching.

I myself broadened my intellectual view in those Berkeley years partly as a survival mechanism. Realizing that my expertise in documentary and in gender and sexuality did not align well with the job market, I redirected my attention to broadening rather than deepening my knowledge. I developed - largely on my own, without much curricular infrastructure - an additional specialization in digital media studies. ${ }^{6}$ This became a central component of my dissertation (and now the book Dying in Full Detail: Mortality and Digital Documentary) and my most marketable attribute on the job market. ${ }^{7}$ I began with the small corner of digital media studies most relevant to my research, learning about digital video cameras and streaming video platforms used by amateur documentarians. But from there, what had once been strategic became a joyful way of

5 This was basically the situation at my own institution, Smith College, as Alexandra Keller ably sustained a film studies program as the only permanent faculty member in the college with a film PhD from 2002 until my hiring in 2016.

6 Kristen Whissel's graduate course Cinema and the Digital was a notable exception, and her own move into research on digital cinema made her a strong influence and resource for me.

7 Jennifer Malkowski, Dying in Full Detail: Mortality and Digital Documentary (Durham, NC: Duke University Press, 2017). 
life. My claim to working on digital media studies compelled me to hold myself more accountable to the scope of that huge field, expanding first into teaching and then into researching on digital cinema, video games, GIFs, and social media.

There are downsides to working so broadly. Sacrificing a certain degree of depth for breadth means more noticeable gaps in your knowledge and getting things wrong at a greater rate. By occupying so many distinct subfields, I feel the pangs of imposter syndrome more sharply than I probably would with a narrower concentration. And I have to work very hard to acquire at least a minimal depth of knowledge within each of these subfields if I want to teach or write on them. The life of the dilettante is much less relaxed than its reputation! Scholars with a broad research profile also have to develop a clear sense of what makes their work cohere in order to advocate for themselves in getting jobs and promotions. On an institutional level, such research profiles raise questions for tenure: Who is best qualified to review tenure files with broad publishing on film, video games, Internet video, and social media? Will all reviewers be open to the value of work that falls outside their own area of expertise? But the advantages are overwhelming, including the pleasure of connecting with colleagues from across the wide ecosystem of SCMS.

Further, my background in cinema studies and the longer history of visual culture has greatly enriched my new work with digital media, as I am in a position to see clearly the legacies of old media in new ones. This, of course, is the benefit of dilettantism: the cost of dividing our attention laterally buys us a map of multiple subfields' terrain. We cannot know as much about any one of these subfields as the focused experts, but we can bring them together in ways that the experts in their separate intellectual silos cannot. I bring in the well-worn metaphor of the silo here to acknowledge that there is nothing new about a call for scholars to work more broadly. What's new, though, in cinema and media studies is the urgency of our need to do so, as our objects of study rapidly multiply and interact with each other to an unprecedented degree in our convergence culture.

While thinking broadly can have major research benefits, I believe its most essential and rewarding role is in the classroom. I've described the way SLAC faculty have long embraced teaching broadly through their mandate that each faculty member cover huge areas of the cinema and media studies curriculum. But I've come to believe in recent years that we should all be striving for greater breadth within individual classes, not just through a broad offering of single-topic courses. For example, film, television, video games, Internet media, and so on are incredibly intertwined in most of our daily lives and the lives of our students. So how do we justify keeping them consistently apart in distinct courses in most of our curricula? When we allow ourselves to teach this way, we narrow our own thinking about the connections among media and we put the burden of making those connections wholly on our students.

Those of us teaching the introductory course for expanded cinema and media studies departments are no doubt already doing this pedagogical work within at least that one course. We would serve our students well to infuse that mode of teaching more fully throughout our curricula. At Smith College, I am part of a core faculty of two, where I'm working to help transform our former Film Studies program into Film and Media Studies. In navigating that shift, I'm pushing myself to construct 
my courses broadly. I structured our redesigned introductory course around a progression of pairings of methods and media: the aesthetics of film, the history of television, the ideologies of video games, and the technology of Internet media. I then show students how to reshuffle that deck, guiding them through projects that explore, say, the history of video games or the ideologies of television. Beyond the introductory level, my course Linking Film and Digital Media is explicitly about cross-media and cross-historical connections. It brings together nineteenth-century visual culture, celluloid cinema, digital cinema, video art, mapping software, and video games to reveal how old media continue to influence new media and how the digital media that cinema collaborates and competes with are reshaping it. My three years in comparative media studies (which provides another useful model) at Miami University pushed me to design courses in this mind-set and to figure out what remains fundamental to media across histories, cultures, and technologies. In that spirit, I designed our introductory Comparative Media Studies course with thematic units providing a selection of answers to the question: Why do human beings create and consume media? Examining the desire to master time, the desire to traverse space, the desire to change minds, and the desire to remediate, my students and I found meaningful connections among media objects from 1840 to today, from Brazil to Japan to Fiji to US Amish communities, and from podcasts to medical imaging to phénakistiscopes to mobile phone apps. We studied what unites rather than what divides our vast field while we still attended daily to medium-specificity and robust contextualization.

To return to the example I began with of the interloping nonexpert, I'm currently building a gaming lab at Smith. Even though I hardly know any other faculty here who are teaching on video games, I can't wait to be "intruded upon" by nonexperts who want to teach with the lab - that is, curious professors from across disciplines who can get past the technological intimidation of this medium and see its relevance to their own subject matters. I would welcome and support their efforts to learn just enough about games to start bringing them into more classes. And I'm always grateful to meet a fellow dilettante.

Cinema and media studies has grown so vast that none of us sees its whole panorama anymore, if ever we could. That doesn't excuse us from making the effort of climbing at least a few stories skyward to get a better vantage point. This way of thinking isn't for everyone. I recognize that some may see it as capitulating to the implicit demand in our current environments - both media and academic environments - to constantly divide our attention or to perform more kinds of labor. But, my goodness, is it ever an exciting time to be reading and teaching and writing broadly. It is a sheer pleasure - and a rare privilege our career affords - to be learning truly new ideas all the time. This feeling of exuberance itself is not new but old. It is reminiscent for me of the sharp intellectual excitement of my own years as a SLAC student at Oberlin (an excitement I see in many of my Smith students today). More broadly, it is reminiscent of the feeling accompanying media themselves in their shiny early years, as Walter Benjamin articulated in the 1930s better than anyone has since: "Our taverns and our metropolitan streets, our offices and furnished rooms, our railroad stations and our factories appeared to have us locked up hopelessly. Then came film 
and burst this prison-world asunder by the dynamite of the tenth of a second, so that now, in the midst of its far-flung ruins and debris, we calmly and adventurously go traveling." ${ }^{\text {I }}$ hope that more of us in cinema and media studies today will feel the pull to "calmly and adventurously go traveling."

8 Walter Benjamin, "The Work of Art in the Age of Mechanical Reproduction," in Illuminations, trans. Harry Zohn, ed. Hannah Arendt (New York: Schocken Books, 1968), 236.

\title{
Feminism and the Big Picture: Conversations
}

\author{
by SANGITA GOPAL
}

W

hen invited to contribute to an In Focus section in which Lucas Hilderbrand asked us to reflect on "the state of the field and whether it has expanded to the point where it is hard to keep track of the 'big picture' and take stock of the critical and political stakes of studying media old and new," I started reading the history of SCMS. A previous In Focus contribution by Jacqueline Stewart struck me as particularly significant, not only for noting how feminist scholars in the late 1970s and 1980s had transformed the study of film by giving it a social and political orientation and had helped to institutionalize it, but also in outlining the rewards and risks of such incorporation - especially for "the minority." She suggests that "minority" subjects - human and scholarly - continue to occupy liminal spaces in the field, and productively so," while also emphasizing that "the recruitment and cultivation of scholars of color and scholarship on race must continue to be an organizational and fieldwide priority."1

Women, who constitute about a half of the membership of SCMS, are by no means a minority, and feminist perspectives were critical in the formation of media studies. So, in a sense the grand narrative that feminism has done its job both vis-à-vis the field and the institution is valid. However, because that narrative was never really grand but diverse, fractured, and contentious; because it was never only about equity but also about difference; because women-of-color

1 Jacqueline Stewart, "The Scholars Who Sat by the Door," Cinema Journal 49, no. 1 (2009): 147-148. For a history of women's institutional labor and leadership in SCMS, see Ramona Curry, "A Brief History of the MS in SCMS," Camera Obscura 63 (2006): 159-165; Anna Froula, “Women's Work," Cinema Journal 55, no. 4 (2016): 1-2. 
Copyright of Cinema Journal is the property of University of Texas Press and its content may not be copied or emailed to multiple sites or posted to a listserv without the copyright holder's express written permission. However, users may print, download, or email articles for individual use. 